\title{
Malcolm Lowry en el ocaso del imperio
}

\author{
Nair María Anaya Ferreira \\ Universidad Nacional Autónoma de México
}

Resumen

Este artículo propone una lectura de Bajo el volcán, de Malcolm Lowry, centrada en la importancia de la historia moderna y la presencia del Imperio Británico en la narración del último día de Geoffrey Firmin. Siguiendo la noción de una "lectura contrapuntística" de los textos canónicos ingleses formulada por Edward Said, planteo que al haber nacido en la India, el Cónsul (británico) no logra tener un sentido de pertenencia a la Gran Bretańa, sino que se encuentra en una situación intersticial y liminal que anticipa la ruptura entre una identidad imperial y una identidad nacional, una de las problemáticas mayores abordadas en los estudios teóricos actuales sobre la identidad (especialmente en los estudios poscoloniales). Desde esta perspectiva, el énfasis en situación imperial permite una lectura que rompe con las interpretaciones de México como un "paraíso infernal” que ha perpetuado el estereotipo de nuestro país incluso en estudios críticos sobre el novelista.

Palabras clave: Malcolm Lowry ¿escritor poscolonial?, México en la literatura inglesa, análisis del discurso colonial, identidades poscoloniales, modernismo y ocaso del imperio. 


\section{Abstract}

The purpose of this article is to offer a reading of Malcolm Lowry's Under the Volcano focused on the importance of modern history and the presence of the British Empire in the narration of the last day of Geoffrey Firmin. Following Edward Said's notion of a "contrapuntal reading" of canonical texts, my view is that being an Anglo-Indian, the (British) Consul lacks a sense of belonging in regard to a British identity. He lives, therefore, both in a interstitial and a liminar situation which anticipates the breaking up between a sense of national identity and a sense of imperial identity, which constitutes, in fact, one of the main subjects in contemporary theoretical studies about identity (especially in Postcolonial Studies). From this point of view, the current interpretation breaks with a very common reading of the novel in which Mexico is just seen as an "infernal paradise", an image which has perpetuated a degrading stereotype of the country, even in some serious critical studies about the author.

Keywords: Malcolm Lowry, postcolonial writer?, Mexico in English Literature, Analysis of colonial discourse, Postcolonial identities, Modernism and the fall of empire.

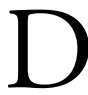
entro de la tradición literaria inglesa, Malcolm Lowry (19091957) es un autor excéntrico. Si bien su obra cumbre Under the Volcano (Bajo el volcán) (publicada en 1947) quedó incluida como parte de las 100 mejores novelas en inglés del siglo XX, lista publicada por la "Modern Library" (parte del grupo editorial de Random House), es difícil encontrar el nombre de Lowry o de su obra dentro de las historias literarias de la novela inglesa moderna. Ciertamente, no aparece como parte de la controvertida disquisición acerca de las grandes obras de la tradición occidental propuesta por Harold Bloom, quien ni siquiera considera a Lowry como una posibilidad para su "profecía canónica" (Bloom, 1994). La recepción en México, por otra parte, lo ha convertido en un 
autor de "culto" y sus lectores suelen concentrarse en dos aspectos fundamentales: el alcoholismo de Lowry y su protagonista, y la importancia del escenario mexicano como un paraíso infernal (la combinación, a veces trillada, de una simbología relacionada con la muerte y la violencia, y la imagen de México como un país violento e ingobernable). Este último punto constituye también el lente a través del cual suelen enfocarse los críticos de habla inglesa que exploran la imagen de México en la narrativa de los autores ingleses que vinieron a nuestro país en las primeras décadas del siglo XX: D.H. Lawrence, Graham Greene, Aldous Huxley, Evelyn Waugh y, por supuesto, Lowry (Veitch, 1978; Walker, 1978). Hay una explicación clara para este tipo de lectura, pues el mismo Lowry - en la famosa carta que escribió a su editor Jonathan Cape el 2 de enero de 1946 para defenderse de las acusaciones hechas por el dictaminador y que habían llevado a que la novela no fuera aceptada para ser publicada - dio prioridad a los aspectos simbólicos y alegóricos de la novela, entre los cuales destacaba la función de México como

lugar de encuentro [...] de la humanidad misma, pira de Bierce y trampolín de Hart Crane, arena milenaria de conflictos raciales y políticos de toda índole, y donde un colorido y genial pueblo autóctono tiene una religión que podemos describir burdamente como una religión basada en la muerte, al menos tan apropiada como Lancashire o Yorkshire, para situar nuestro drama de la lucha de un hombre entre los poderes de la oscuridad y la luz. Su lejanía con respecto a nosotros, así como la semejanza de sus problemas con los nuestros, contribuirán a su modo, a la tragedia. (Lowry, 1967: 67)

Sin embargo, hay un aspecto que ha sido poco tratado por los críticos y que, en mi opinión, puede ofrecer otras posibilidades de lectura de esta novela magistral. Si tomamos como punto de partida el enfoque "contrapuntístico" que sugiere Edward Said 
para la lectura e interpretación no sólo de las obras canónicas de la tradición europea, sino incluso del archivo completo de Europa y Estados Unidos, podremos apreciar que, en Bajo el volcán, Lowry no sólo muestra una percepción extraordinaria de las repercusiones del fenómeno de expansión imperial en el mundo moderno sino que, además, tiene una postura radical con relación a dicho fenómeno. Esto resulta paradójico pues, en cierto sentido, Bajo el volcán forma parte del archivo del "discurso colonial", es decir, de aquellas obras sobre las regiones "exóticas" del planeta que permitían a los europeos establecer una distinción entre "nosotros" y los "otros". Sin embargo, al mismo tiempo, su posición crítica anticipa algunas de las temáticas que ahora son analizadas por perspectivas crítico-teóricas asociadas con los estudios poscoloniales.

El propósito de este ensayo será analizar la forma en que Lowry elabora un contradiscurso que cuestiona seriamente algunos de los principios ideológicos de su tiempo, en especial el del concepto de "Englishness" (anglicidad) como parte del complejo entramado político y cultural que sustentó el fenómeno de expansión imperial británico. Así, en el caso de Bajo el volcán, la lectura contrapuntística propuesta por Said -es decir, "el esfuerzo por extraer, extender, hacer hincapié y darle voz a lo que está en silencio o sólo presente de forma marginal o representado ideológicamente en [los textos coloniales]... Al leer un texto, [el lector] debe abrirlo tanto a todo lo que el autor le introdujo como a lo que dejó fuera” (Said, 1993 : 66-67) — consiste en analizar la forma en que la expansión imperial británica afecta la vida de los protagonistas y permea el desenvolvimiento de la trama a tal grado que obliga a modificar (o al menos matizar) la trillada interpretación crítica de México como "paraíso infernal". Mi propuesta es que, si bien el escenario mexicano del Día de Muertos en el periodo cardenista funciona como correlato en la novela, la caída de Geoffrey Firmin se debe a que éste vive las tensiones ocasionadas por el ocaso del 
imperio, las cuales provocan en él un sentido de enajenación del cual no puede escapar. La primera de estas tensiones, como argumentaré más adelante, surge del hecho de que el "British Consul", el Cónsul inglés, no es, en realidad inglés, sino anglo-indio, y esto provoca un estado de neurosis — causado por el abandono y la migración forzada - que, en primera instancia, lo hace vivir con una sensación permanente de desarraigo, lo cual, a su vez, lo convierte en un "fracasado" dentro del servicio civil de carrera británico y, finalmente, lo conduce a la muerte.

En cuanto al uso de México como local exótico, al igual que el peregrinar de Lowry por algunos países, como he argumentado con anterioridad (Anaya, 2001), no constituyen hechos extraordinarios, sino que forman parte de una larga tradición británica (y europea) en la que el exotismo contribuyó a acentuar el sentido de pertenencia a la "civilización", ya fuera con una aceptación acrítica por parte de sus exponentes o bien como medio para cuestionar y relativizar ciertos valores europeos (en especial lo relacionado con la sexualidad y el deseo). Además de la necesidad de encontrar escenarios exóticos, la presencia en México de D. H. Lawrence, Aldous Huxley, Arthur Calder-Marshall, Graham Greene, Evelyn Waugh y Ralph Bates tenía, en todos los casos, un fin ulterior. Lawrence, por ejemplo, estaba en la búsqueda permanente de un sitio ideal donde ubicar su comunidad utópica: Rananim; Huxley quiso seguir los pasos de su mentor, Lawrence; Greene y Waugh tenían la clara consigna de desprestigiar el gobierno de Cárdenas; Bates, al contrario, tenía una postura socialista y vino a México patrocinado por el Partido Comunista; Lowry fue el único que llegó a México por necesidad, buscando, simplemente, un lugar en el que la mesada paterna rindiera más. Desde esta perspectiva, incluso Bradbury, quien considera a Lowry como escritor modernista (Bradbury, 1973), insiste en que su caso es extraordinario, pues su exilio autoimpuesto no fue a las importantes capitales europeas — como en 
el caso de Joyce, Beckett o Durrell— sino que implicó un transitar azaroso que lo condujo a un país periférico, visto por los europeos en la década de 1930 como "primitivo y exótico" y en el que, para colmo, los intereses comerciales británicos se veían afectados de forma radical. En resumen, a pesar de no ser una colonia inglesa, México constituía una especie de extensión del imperio debido a la influencia ideológico-financiera ejercida desde fines del siglo XIX y este hecho, lo sabemos bien, será central para el desarrollo de la trama en Bajo en volcán. Desde esta perspectiva, el primer párrafo de la novela establece las coordenadas de la expansión imperial con respecto al continente americano y conecta - aunque el lector no lo sabe en ese momento- los lugares de nacimiento y muerte de los protagonistas, Geoffrey Firmin e Yvonne:

Dos cadenas montañosas atraviesan la República, aproximadamente de norte a sur, formando entre sí valles y planicies. Ante uno de estos valles, dominado por dos volcanes, se extiende a dos mil metros sobre el nivel del mar, la ciudad de Quauhnáhuac. Queda situada bastante al sur del Trópico de Cáncer; para ser exactos, en el paralelo diecinueve, casi a la misma latitud en que se encuentran, al oeste, en el Pacífico, las islas de Revillagigedo o, mucho más hacia el oeste, el extremo más meridional de Hawaii y, hacia el este, el puerto de Tzucox, en el litoral Atlántico de Yucatán, cerca de la frontera de Honduras Británicas o, mucho más hacia el este en la India, la ciudad de Yuggernaut, en la Bahía de Bengala (Lowry, 1964: 9).

Es en relación con este espacio que Lowry establece el contrapunto entre la especificidad del paisaje de Quauhnáhuac (y los hechos concretos acontecidos en el Día de Muertos de 1938) y la aparente opacidad de los otros lugares mencionados, los cuales no sólo encarnarán el pasado de los protagonistas sino que serán simbólicos del fenómeno colonial en general. A lo largo del artículo me 
propongo explorar la forma en que Lowry otorga un alto nivel de significación a estos lugares como parte de las constantes analepsis que tanto disgustaron al lector de Jonathan Cape. Al no formar parte de la sucesión cronológica de los desencuentros y las desventuras del 2 de noviembre de 1938 y, por tanto, al desviar la atención del escenario mexicano y su simbología, dichas analepsis podrían parecer excesivas, si no fuera porque constituyen los cimientos de la catedral churrigueresca con la que Lowry comparó la estructura de su novela (Lowry, 1967: 88). Por medio de este recurso narrativo, Lowry ofrece vislumbres de la vida de sus protagonistas antes de su llegada a México e incorpora el tema del desarraigo y la ruptura de identidad ocasionada por el fenómeno colonial, con lo cual anticipa una de las grandes preocupaciones de la actualidad. Al explorar, en especial, los conflictos internos de Geoffrey y Hugh Firmin, Lowry parece predecir lo que Gayatri Spivak escribe sobre las identidades poscoloniales y diaspóricas: "empire messes with identity", es decir, el imperio afecta y arruina la identidad tanto de los colonizados como de los colonizadores (Spivak, 1993: 226). El alcoholismo del Cónsul no es más que la manifestación evidente, la punta del iceberg, de una problemática más profunda. Por un lado, sufre, al igual que Rudyard Kipling y George Orwell, las consecuencias de las tensiones vividas por los hijos de funcionarios británicos: nacen en la India y forman parte de un grupo que, si bien tiene ciertos privilegios, tampoco alcanzan la cima en la escala social. En la India, sienten nostalgia por el hogar (Inglaterra), pero son vistos por la población local como extranjeros y usurpadores. Paradójicamente, el regresar a Inglaterra, se encuentran con que tampoco encajan como ciudadanos británicos, con lo que, como bien demuestra Simon Gikandi en Maps of Englishness, se produce una ruptura entre las nociones de "imperio" y "nación-estado" (Gikandi, 1996). Dicha ruptura es perceptible en las figuras de 
Geoffrey y Hugh, cuya identidad es, simultáneamente, intersticial y liminar.

En este sentido, es posible afirmar que no es gratuito que Lowry haya creado su obra maestra empleando algunas de las estrategias narrativas del modernismo - no sólo en aspectos formales como la estructura circular de la narración, la multiplicidad de perspectivas, la densidad intertextual (proveniente de fuentes dispares y alejadas entre sí), las constantes rupturas en la temporalidad de la narración, el uso del monólogo interior o bien el énfasis expresionista en la distorsión y lo grotesco- sino especialmente en la recreación de una angustia existencial ocasionada por el deterioro moral del entorno. Comparte así con Joseph Conrad y E. M. Forster, por ejemplo, las características que Said adjudica a la cultura modernista como una respuesta a las presiones que el imperio impuso a la cultura en general; es decir, comparte con algunos de sus contemporáneos el hecho de que sus obras abarcan "desde la experiencia triunfalista del imperialismo hasta los extremos de la autoconciencia, la discontinuidad, la autorreferencialidad y la ironía corrosiva”, que ponen en duda el éxito de la empresa imperial (Said, 1993: 188-189). Mi planteamiento aquí es que Lowry crea un complejo entramado mediante el cual socava los valores imperialistas, en especial, algunas nociones como la importancia y el triunfo de las expediciones misioneras o científicas, la efectividad del colonialismo o, bien, atributos como el valor, la responsabilidad o la templanza (atributos que suelen formar parte de la noción de "Englishness" o "anglicidad").

La crisis de identidad de Geoffrey y Hugh tiene raíces en una alienación múltiple, que empieza con el hecho de haber nacido en la India, haber quedado huérfanos y haber sido abandonados por el padre, quien "desapareció tan sencilla como escandalosamente. Nadie llegó a saber con precisión en Cachemira, ni en ninguna otra parte, lo que había ocurrido. Un buen día ascendió el Himala- 
ya y se esfumó, dejando en Srinagar a Geoffrey con su hermanastro Hugh — que a la sazón era un nińo en brazos...” (Lowry, 1964: 9) La sensación permanente de abandono acompañará a estos personajes a lo largo de su vida. Para Geoffrey, además, se genera un sentido de culpa por no haber cuidado al hermano (hay cerca de diez años de diferencia entre ellos). Pasan por varias familias adoptivas y finalmente quedan separados: Hugh es cuidado por la tía paterna, mientras Geoffrey realiza sus estudios universitarios y empieza a trabajar en el Servicio Diplomático (lo que trunca sus deseo de incorporarse al Servicio Civil de la India). A partir de algunos detalles relacionados con estos episodios, Lowry ofrece una visión más amplia de la identidad fragmentada y autodestructiva de los personajes, que presenciamos en la narración del último día de vida del Cónsul, pero además elabora un contrapunto irónico (en ocasiones satírico) de todo proceso de colonización, incluyendo un asunto que en la actualidad es un tema teórico fundamental en Gran Bretańa: el del desfase de un sentido de pertenencia a un concepto de estado-nación que hasta hace algunas décadas estaba asociado de forma inminente al de una identidad imperial.

Lowry emplea varias estrategias para desarrollar estos temas y vincularlos a la atmósfera trágica que permea toda la trama. Una de ellas es la presentación indirecta de los aspectos biográficos de los personajes, ya sea por medio de los recuerdos de alguien más (por ejemplo, en el primer capítulo, los recuerdos de Laruelle sobre su juventud con el Cónsul, cuando éste acababa de llegar a Inglaterra después de la desaparición de su padre y la muerte de su madrastra) o como parte de las alucinaciones de Geoffrey. Quizá el único caso en que las memorias provienen claramente del personaje ocurre en el capítulo seis, en el que Hugh hace un largo recuento de su vida, sus frustraciones y su sentimiento de fracaso, sobre todo por no haber renunciado a sus ideales. No hay que olvidar que la estrategia narrativa de la novela consiste en un narrador 
heterodiegético que se introduce a tal grado en la mente de los personajes que en ocasiones (como sucede en el episodio del jardín con el señor Quincey) es casi imposible distinguir, incluso a nivel gramatical, cuándo es el narrador el que relata y cuándo estamos dentro de la mente del protagonista. Aunado a lo anterior, cada capítulo se focaliza primordialmente en uno de los cuatro personajes y es a través de cada uno de ellos que percibimos y conocemos los sentimientos, pensamientos, sensaciones y reacciones del personaje en cuestión y de los demás. En este sentido, la narración de Bajo el volcán pertenece a lo que Dorrit Cohn ha denominado "psiconarración”, y está mediada por un narrador que suele permanecer oculto y se fusiona con facilidad con la conciencia que está narrando (Cohn, 1978: 26). Dicha estrategia permite a Lowry no sólo tener una flexibilidad temporal casi ilimitada (Cohn, 1978: 34) sino que sostiene la compleja estructura temporal y espacial que han señalado algunos críticos: por un lado, la narración mimética de la trama, con un ritmo cronológico claramente establecido y, por otro, el entramado solipsista y simbólico que rompe muchas veces con el flujo temporal (Wood, 1980: 150 y Grace, 1982: 154-155). Las innumerables referencias intertextuales y los motivos recurrentes, además, dan coherencia a la obra en un nivel más profundo pues establecen el tono trágico (con toques de comedia) y grotesco de la novela; construyen las paradojas que giran en torno a la vida y la muerte, pero sobre todo, al cómo vivir; producen la creciente sensación de angustia y opresión vinculada con la situación mundial (la Guerra Civil española, el inicio de la Segunda Guerra Mundial y el Holocausto, la inestable situación política y social en México); recrea el ambiente histórico-cultural de México y el mundo (al grado que podemos reconstruir la música popular del momento, incluyendo "Guadalajara" tocada por mariachis, o bien los cromos, calendarios y anuncios tan característicos de nuestro entorno); pero sobre todo, profundiza en la caracterización de los 
personajes, pues establece una serie de valores ideales (incluso virtudes en el sentido cristiano) de los que los protagonistas están conscientes pero que no logran alcanzar. En conjunto, todo esto contribuye a la ironía punzante con la que Lowry desmitifica las glorias de la expansión imperial y que, en palabras de Peter Nicholls, constituye una de las herramientas primordiales contra la modernidad (2009: 5).

En lo que se refiere a la forma en que Lowry se distancia del imperio me concentraré en el contrapunto que se produce entre las alusiones a la figura de Fausto y el Quijote con las alusiones a Joseph Conrad, en especial a su novela Lord Jim, así como en los motivos temáticos relacionados con historias fallidas de colonización y con exploradores fracasados. El factor subyacente en estos elementos es una noción de idealismo que toma diferentes formas pero que al mismo tiempo es socavado por las acciones de los personajes y por otras referencias históricas y literarias. En un sentido primario, se encuentra como representación del idealismo más elemental de la novela, el amor de Geoffrey e Yvonne que cae junto con las figuras de paja del Quijote cuando, en el capítulo tres, el Cónsul, con toda conciencia, sabe que seguirá bebiendo a pesar de la llegada sorpresiva de su esposa después de un año de ausencia. Dicha decisión llevará a la imposibilidad de comunicación entre la pareja y a su ruptura final (Lowry, 1964: 103). Sin embargo, el tema quijotesco queda como una de las melodías contrapuntísticas para el idealismo desinteresado y altruista de un amor por el próximo que nunca logra concretarse en la novela, y queda no sólo implícito en todas las referencias a la parábola del "Buen Samaritano" (en especial el nombre del barco en el que Geoffrey vivió una experiencia traumática que mencionaré a continuación, y el trágico episodio del capítulo ocho, cuando nadie hace nada por ayudar a un indio recién asesinado), sino que es visto por Hugh como su mayor fracaso. De igual forma, los valores éticos y mora- 
les a los que renuncia el Fausto de Christopher Marlowe cuando elige el conocimiento oculto y deja de lado las disciplinas renacentistas, además del pecado de la soberbia y la falta de capacidad para solicitar el perdón divino y alcanzar la redención, anuncian la naturaleza de la caída del Cónsul. Lo que permea entonces es un sentido permanente de culpa que se asocia, por supuesto, con la culpa original y la expulsión del Edén.

Dentro de este marco simbólico, la caracterización del Cónsul (y su complemento, su hermanastro Hugh) parte de una ambigüedad que subyace en toda la trama y que es presentada por Jacques Laruelle (el cineasta francés fracasado) en el primer capítulo, atormenta a Geoffrey a lo largo de la narración y es recordado vagamente por Hugh en el capítulo seis: en su juventud, a bordo de un barco de la marina mercante llamado SS Samaritan, buque "proveniente de Shangai con rumbo a Newcastle y Nueva Gales del Sur, cargado de antinomio y mercurio y wolfran, había seguido una ruta asaz extraña" y, fuera de rumbo, se había topado con un submarino alemán. El Samaritan, aparentemente sin armas, no había opuesto resistencia, pero de súbito "[c]omo por obra de magia, el cordero se convirtió en dragón que escupía fuego. El submarino ni siquiera tuvo tiempo de sumergirse. Capturaron a toda la tripulación". El capitán murió en el combate y, por alguna razón inexplicable, se consideró que Geoffrey Firmin como el héroe de la operación, por lo que se le otorgó "la Orden o la Cruz Británica por Servicios Distinguidos" (Lowry, 1964: 40). Sin embargo, el episodio siempre quedó con la incógnita de la suerte de los alemanes capturados: "Algo había ocurrido a aquellos oficiales alemanes y lo acontecido no era para relatarse. Los secuestraron se dijo- los fogoneros del Samaritan, quienes los quemaron vivos en las calderas" (Lowry, 1964: 41). A pesar de que Firmin quedó absuelto por un Consejo de Guerra, el sentimiento de culpa no lo abandona nunca y queda como la gran ambigüedad de la novela: 
¿fue responsable o no el Cónsul de dicho acto? En dado caso, ¿este tipo de actos son permitidos en una situación bélica?

De ahí que la alusión a Lord Jim, de Joseph Conrad, desempeñe una función simbólica significativa. En relación con Hugh, con quien está mayormente asociado, funciona de manera paródica: Hugh (que ni siquiera ha leído la novela) realiza el viaje sin incidentes a los Mares del Sur tratando de encontrar el tipo de aventura conradiana. Su vida es tan insignificante que no logra ninguno de sus objetivos (ni tocar guitarra, ni componer, ni volverse periodista serio ni, peor aún, participar solidariamente en la Guerra Civil Espańola). Vaga por la vida sin responsabilidad, a pesar de tener una postura crítica de izquierda sobre el imperio y la colonización. De hecho, suele perder sus documentos, en especial, el pasaporte (como cuando el Cónsul todavía en un puesto digno en París se lo restituye), lo cual tendrá repercusiones trágicas al final de la novela cuando dichos documentos aparecen en El Farolito en el saco del Cónsul, por lo que Geoffrey es acusado de espía comunista y asesinado arteramente. Por otra parte, en relación con el Cónsul mismo, Lord Jim no sólo incrementa la atmósfera de angustia existencial ocasionada por la traición y la culpa sino que, por medio de los paralelismos entre las acciones de Jim y de Geoffrey, vincula a Lowry con las preocupaciones éticas del mismo Conrad con respecto al imperio. Jim abandona un barco lleno de musulmanes a punto de hundirse. El barco finalmente es rescatado y Jim tiene que vivir con la vergüenza de su cobardía y de haber traicionado el código de los marinos (tema apreciado por Conrad). Decide entonces redimirse y se convierte en una especie de gobernador paternalista de los nativos de Sumatra, hasta que es traicionado por otro europeo y los nativos lo asesinan. Sin embargo, a diferencia de Conrad, de quien mucho se ha escrito acerca de su falta de empatía con esas regiones exóticas y los nativos que las habitan, el Cónsul está tan inmerso en su embriaguez y es, en el fondo, un persona- 
je tan vulnerable, que rompe con esos estereotipos del discurso colonial (los cuales, en la obra mexicana de Lawrence, Greene, Huxley y Waugh eran completamente denigrantes). Si en Conrad el dilema de sus protagonistas tiene que ver con un vacío interno que hace que la vida carezca de sentido, en Lowry, en mi opinión, el dilema se debe a que el Cónsul vive, según lo percibe la ciudad de Quauhnáhuac, en palabras del señor Bustamante: "en continuo terror por su vida" (37) debido "a las fuerzas en el hombre que lo hacen vivir aterrorizado de sí mismo" (Lowry, 1967: 66).

La función del Samaritan, así como de los buques en los que Hugh realiza su larga (y en momentos aburrida) travesía por los Mares del Sur, constituye, ciertamente, una de las actividades principales del imperio: llevar materia prima de las regiones periféricas a las metrópolis. El espacio abierto de mar y tierra queda, así, incautado por las potencias europeas en actos que son descritos, retóricamente, como parte del progreso de la humanidad. Sin embargo, en Bajo el volcán, dicha apropiación se ve socavada de forma constante y ofrece un comentario irónico a la situación vivida en México a lo largo su historia y, específicamente, en 1938. Si el ronquido alcoholizado del Cónsul representa en algún momento, como piensa Hugh "la voz en sordina de Inglaterra sumida en largo sueño" (Lowry, 1964: 111), entonces la situación del Imperio Británico dista mucho de la gloria de la expansión, idealizada discursivamente. El mismo Hugh le comenta a Yvonne un poco después, durante su cabalgata, "[si] las sendas de la fama no llevan sino a la tumba [...] sea España la tumba do nos lleve el renombre de Bretaña" [sic] (Lowry, 1964: 108) [En el original: "If the paths of glory lead but to the grave [...] then Spain's the grave where England's glory led" (Lowry, 1947: 108)]. Basado en el famoso poema de Thomas Gray, "Elegy written in a Country Churchyard", en el que el autor del siglo XVIII hace un comentario sobre el destino humano, Hugh muestra su preocupación por las reper- 
cusiones políticas de las relaciones y tratados internacionales: durante la Guerra Civil espańola, Lord Neville Chamberlain, quien en algún momento coqueteó con Hitler, firmó también en 1936 un tratado de no intervención extranjera en España, que afectó a los republicanos y, desde la perspectiva de Hugh condujo a la larga "Batalla del Ebro", la cual concluyó el 16 de noviembre de 1938 (de ahí el motivo asociado con Hugh en la novela: "Están perdiendo la batalla del Ebro").

La falta de responsabilidad y ética del imperio es lo que ha convertido al Cónsul en lo que es. Incluso su lugar sońado, en Canadá, donde al parecer es incluso dueño de una isla (en Columbia Británica), es producto de la avaricia capitalista, como piensa Hugh en su conversación con Yvonne, cuando sueñan con escapar de México para librar a Geoffrey de la bebida:

Supongamos que desembarcas en Vancouver, lo cual parece razonable. Hasta allí todo va bien. A McGoff no le importaba mucho el Vancouver actual. Según él, tiene cierto aspecto a la Pago-Pago con mezcla de salchichas y puré de papa y generalmente un ambiente bastante puritano. Todos están profundamente dormidos, pero si picas a alguien, surgen de la madriguera agitando la bandera inglesa. Pero en cierto sentido, nadie vive allí. Es como si todos simplemente estuvieran de paso. Minan el país y se largan. Hacen estallar la tierra en añicos, abaten los árboles y los mandan rodando cuesta abajo por el estuario de Burrard... (Lowry, 1964: 136)

Para escapar cualquier sitio de la tierra es apropiado, ya sea porque puede ser colonizado fácilmente o porque forma parte del imperio. Da lo mismo Canadá que Honduras Británicas, Freetown en África Occidental Británica o Trinidad en las Indias Orientales, Tristán da Cunha o la isla de enfrente, Gough, que está deshabitada y la familia Firmin podría colonizarla, o bien Sokotra "que producía incienso y mirra y donde los camellos trepaban como gamuzas... 
mi isla predilecta en el mar Arábigo" (Lowry, 1964, 134). Lo mismo ocurre con los lugares por los que han transitado Hugh, en su peregrinar sin rumbo, o Geoffrey cuya labor diplomática fue tan mediocre que el Servicio Diplomático lo fue confinando "a cargos consulares cada vez más remotos, hasta que por último le concedieran la sinecura de Quaunáhuac, por tratarse de un puesto en el que existían menores probabilidades de que fuera a causar molestia al Imperio en el que creía tan apasionadamente - cuando menos con parte de su pensamiento, según lo sospechaba Laruelle" (Lowry, 1964: 39).

Las sospechas de Laruelle, como queda de manifiesto a lo largo de la trama, no son del todo acertadas, pues el Cónsul se va tornando cada vez más escéptico acerca de la naturaleza y la función del Imperio. Dicha actitud, sin embargo, no es evidente, sino que aparece de forma encubierta en su embriaguez y sus alucinaciones. El hecho de que el Cónsul mantenga una claridad mental casi visionaria dentro de su dipsomanía es justo uno de los logros de la novela. Además de estar plenamente consciente de lo que ocurre a su alrededor (por ejemplo, del paso del tiempo, a veces incluso de los minutos), su asociación imaginaria con las figuras de exploradores perdidos o misioneros que se quedan a vivir entre los indios subvierte el discurso triunfal del imperialismo. Esto se torna especialmente irónico debido a que las alusiones a estas figuras se inscriben en un tono paródico que socava el ideal que deberían representar. $\mathrm{Al}$ mismo tiempo, colocan al Cónsul, de forma permanente, en las fronteras del imperio, como personaje liminal que en realidad es. En uno de los episodios más graciosos de la novela, cuando Geoffrey busca una botella en el jardín de su casa que prácticamente se ha convertido en una selva en la que sólo falta el tigre del pintor Rousseau, Lowry invierte la significación textual de uno de los íconos de la exploración en África, cuando Geoffrey es descubierto por su vecino puritano - “ ${ }^{\circledR} E l$ doctor 
Livingstone, supongo?" (Lowry, 1964: 148) — el estadounidense, nogalero jubilado, señor Quincey, quien representa justo lo contrario de su homónimo decimonónico, el autor de las Confesiones de un comedor de opio. De igual forma, uno de los lugares idílicos con los que sueńa es la Isla Franklin, nombrada así por el líder de la mítica y fracasada expedición a través del Polo Norte (y que constituye, curiosamente, una especie de mito fundador de la identidad canadiense actual. Finalmente, en su aparente locura, Geoffrey crea un alter ego que confirma, por un lado, el rechazo a todo proceso de colonización, pero también, por otro, la idea de que las expansiones imperiales de alguna forma se tragan o hacen desaparecer a quienes desean penetrar en territorio desconocido: el reverendo William Blackstone, colono que llegó a Massachussets en la segunda década del siglo XVII y que se prefirió vivir (y desaparecer) entre los indios en lugar de hacerlo con sus congéneres puritanos británicos. Geoffrey recuerda también a su amigo Wilson y su semblante desesperado "cuando con tanta majestad se separó de la Expedición de la Universidad y desapareció, también en pantalones de smoking, en las más recónditas selvas de Oceanía para nunca más volver..." (Lowry, 1964: 142). No hay que olvidar, además, que Yvonne proviene de Hawái, donde el Capitán Cook murió también a manos de los nativos.

Como se puede ver en lo argumentado con anterioridad, Bajo el volcán dista de ser meramente un retrato de México como "paraíso infernal". Al contrario, podría afirmarse que, dentro del proceso de expansión imperial británico, la construcción de ferrocarriles y la exploración petrolera en México habían convertido a nuestro país en uno de esos lugares periféricos y expoliados que tanto preocupaban a Geoffrey y a Hugh. De ahí que, desde esta perspectiva, sea posible relativizar muchas de las referencias históricas de nuestro país, sucesos sobre los que Lowry tenía una idea bastante clara a pesar de su falta de sobriedad. La primera reflexión crítica sobre el 
colonialismo europeo proviene de parte del francés Laruelle, cuando pasea por el palacio abandonado que ahora es el Jardín Borda y escucha las voces fantasmales de Maximiliano y Carlota: "Laruelle estaba cansado de pesadillas. Francia, pensó, nunca debió trasladarse a México, ni aun bajo el disfraz de los Austria; Maximiliano fue desafortunado hasta en sus palacios. ¡Pobre diablo!” (Lowry, 1964: 21). Y Geoffrey, entre broma y broma, consciente de los problemas agrarios del país y de la presión de las potencias extranjeras le comenta a un confundido señor Quincey:

Sabe, Quincey, a menudo me pregunto si no hay en la antigua leyenda del Jardín del Paraíso, etc., algo más de lo que salta a la vista. ¿Qué tal si Adán no hubiera sido expulsado de aquel lugar? Es decir, en el sentido en el que lo comprendemos [...] ¿Qué tal si su castigo consistiera en realidad — continuó acalorado—- en tener que seguir viviendo allí, solitario, claro está, sufriendo inadvertido, aislado de Dios?... ¿O tal vez — añadió de mejor talante - tal vez Adán fue el primer latifundista, y Dios, de hecho, el primer agrarista, una especie de Cárdenas... ji-ji... lo sacó a patadas? ¿Eh? Sí -y el Cónsul rió entre dientes, consciente, además, de que todo esto no resultaba tan divertido en las actuales circunstancias históricas-, porque es evidente para todo el mundo hoy en día, ¿no lo cree usted así, Quincey? que el pecado original consistió en ser titular de una propiedad... (Lowry, 1964: 149-150)

Con Bajo el volcán podemos afirmar que Lowry anticipa lo que Françoise Král denomina "la crisis de la gran narración de identidad, una crisis que ha sacudido los cimientos de la noción de autenticidad" (Kral, 2009: 52) y que es objeto de estudio de mucha de la literatura poscolonial. Andrew John Miller, en cambio, considera que Lowry participa en la "emergencia de una forma de literatura que puede ser descrita no como global ni poscolonial, sino más bien, como postnacional" (Miller, 2004: 4). En cualquier caso, Geoffrey Firmin en su papel de Cónsul Británico no corres- 
ponde al Geoffrey Firmin desprotegido y abandonado nacido en la colonia británica de la India y en ese sentido es víctima "del proceso de despersonalización causado por el colonialismo" (Bhabha, 1994: 41). El encontrarse en ese punto intersticial en el que el traslape y el desplazamiento de los ámbitos de diferencia sirven para negocian las experiencias intersubjetivas y colectivas del concepto de nación (Bhabha, 1994: 4), Lowry caracteriza un personaje que sólo puede ser construido a partir de la otredad, en un contexto que no es imperial ni británico, lo cual le impide tener cualquier tipo de amarre que lo vincule a una identidad "auténtica."

Como Cónsul Británico, se identifica, de forma un tanto mimetizada y simulada, con la caricatura de inglés que se acerca a rescatarlo cuando cae o, en palabras del narrador: "....repentinamente, la calle de Nicaragua se alzó para encontrarlo" (Lowry, 1964: 89). Al oír una "voz inglesa «muy británica» [que] surgió [...] de detrás del volante [...] de un coche muy bajo que, susurrante, se detuvo a su lado: un M. G. Magma, o algo por el estilo", Lowry identifica la corbata del sujeto que pretende ayudarlo, con el sello distintivo de algún colegio de la Universidad de Cambridge (lo cual construye no sólo un lazo identitario de egresados de dicha universidad, sino una noción de clase y de pertenencia a un grupo privilegiado que pervive hasta nuestros días) y para su sorpresa "se percató de que su propia voz se volvía involuntariamente un poco más "británica»" (Lowry, 1964: 91-92). Al mismo tiempo, sin embargo, comparte algunos aspectos con su hermanastro Hugh de que el sentido de "Englishness" es una especie de farsa, que resume su propio fracaso: "uno es sentimental, enredoso, realista, sońador, cobarde, hipócrita, héroe, en suma inglés, incapaz de seguir las propias metáforas [de dicha identidad]" (Lowry, 1964: 202). Sabe también que en México, en ese momento histórico, es un extranjero en un país extranjero, pero gracias a la expansión imperial siempre existe la posibilidad de encontrar a otro inglés en el mismo lugar. 
Sin embargo, como Geoffrey Firmin, despojado de su papel oficial, el protagonista nunca puede olvidar su país natal y los vínculos afectivos que lo unen a él. Es un hecho notable (y, sorprendentemente, ignorado por los críticos), que una gran parte de las descripciones del paisaje mexicano establecen una analogía con el paisaje de la India, y que, además, los cuadros pintados por la mamá de escenas de Cachemira forman parte de la decoración de su casa. Así, por ejemplo, en la alucinación previa al encuentro con el conductor inglés, en la calle Nicaragua, alusión en la que habla con Hugh, recuerda que "desde que nuestro Padre inició solo el ascenso de los Alpes Blancos y nunca regresó (aunque el caso fue que se trataba del Himalaya y, con más frecuencia de lo que quisiera, pienso que estos volcanes [Popocatépetl e Iztaccíhuatl] me lo recuerdan al igual que este valle me recuerda el Valle del Indo así como aquellos viejos árboles de Taxco con sus turbantes me recuerdan a Srinigar, y como Xochimilco [...] de todos los lugares que vi cuando primero llegué aquí me recordó aquellas casas flotantes en el Shalimar..." (Lowry, 1964: 89). O bien, los jardines Borda le recuerdan al maravilloso jardín mogul de Nishat Bagh, cuyo significado es "jardín de la alegría o del deleite”. Y durante la corrida de toros en Tomalín, cuando ya prácticamente se ha roto la comunicación con Yvonne y Hugh, él piensa sobre dioses védicos, el parecido entre el soma y el mezcal, la llegada de Alejandro Magno a Taxila (cuya pronunciación le recuerda a Tlaxcala) y, para terminar, cómo Cristo llegó a Cachemira y murió allá, en Srinagar. (Lowry, 1964: 333-334). Dentro de las coincidencias que tanto gustaban a Lowry, no deja de ser irónico, dentro de lo grotesco del ambiente de El Farolito, que mientras tiene el acto sexual fallido con la prostituta María, se percata de que hay una historia en español de la India Británica. La última analogía surge ya en el delirio del último suspiro cuando al darse cuenta de que le dispararon y que está teniendo una muerte poco digna, el Himalaya se funde 
con el Popocatépetl y el Cónsul alcanza una redención momentánea, antes de que alguien tire tras él un perro muerto a la barranca. Bajo el volcán es, entonces, un libro que está empapado en la historia de la expansión imperial británica y, como tal, permite no sólo una lectura divergente de la imagen estereotípica de México como "paraíso infernal", sino una apreciación mayor y más profunda de la complejidad textual y temática de esta obra cumbre de mediados del siglo XX. Al mostrar el vasto alcance del Imperio Británico y al subvertir algunos de sus atributos distintivos, como el culto a la aventura y la masculinidad, el motivo de la luz de la civilización, el heroismo moral, la actitud puritana ante el trabajo, la educación elitista en Oxbridge, y el imperio como un espacio que puede ser poseído, representado y convertido en una leyenda vivida y viviente, Lowry trasciende muchas de las actitudes no sólo de Joseph Conrad (que escribía a principios de siglo) sino también de sus contemporáneos que visitaron México y no pudieron escapar de una visión completamente eurocéntrica y racista.

Mediante la caracterización de Geoffrey (y de su contrapunto) Hugh Firmin, ofrece una conmovedora reflexión sobre las consecuencias de la dominación imperial y la falta de responsabilidad de las grandes potencias sobre sus actos. En resumen y citando las últimas palabras que Geoffrey le dirige a Yvonne y Hugh antes de separarse de ellos para dirigirse a su propia muerte:

Hace no mucho tiempo fue la pobrecita e indefensa Etiopía. Antes de eso, la pobrecita e indefensa Flandes. Por no decir nada, claro, del pobrecito e indefenso Congo Belga. Y mañana será la pobrecita e indefensa Latvia. O Finlandia. O la fregada. O hasta Rusia. Lee la historia. Vuelve mil años atrás. ¿De qué sirve intervenir en su curso inservible y estúpido? Semejante a una barranca atestada de desechos que serpea a través de las edades y desaparece en ... ¡Por Dios!, ¿qué tiene que ver toda la heroica resistencia que ofrecen pobres naciones pequeñas e indefensas que, en primer lu- 
gar, se han vuelto indefensas por alguna razón criminal y bien calculada... con la supervivencia del espíritu humano. Nada de nada. Menos que nada. Países, civilizaciones, imperios, grandes hordas perecen sin razón alguna, y su alma y significado perecen junto con ellos para que algún anciano del que quizás nunca hayas oído hablar y que nunca oyó hablar de ellos, que se derrite en Tombuctú y comprueba la existencia del correlativo matemático del ignoratio elenchi con instrumentos anticuados, pueda sobrevivir.

\section{Bibliografía}

Anaya, Nair, 2001, La otredad del mestizaje. América Latina en la literatura inglesa, Facultad de Filosofía y Letras, México, Universidad Nacional Autónoma de México.

Bhabha, Homi, 1994, The Location of Culture, Londres y Nueva York, Routledge.

Bloom, Harold, 1994, The Western Canon. The Books and Schools of the Ages, Nueva York, Riverhead Books.

Bradbury, Malcolm, 1973, "Lowry as a Modernist" en Malcolm Lowry, Under the Volcano, Gordon Bowker (ed.), Houndmills y Londres, Macmillan, Casebook Series, pp. 79-89

Cohn, Dorrit, 1978, Transparent Minds. Narrative Modes for Presenting Consciousness in Fiction, New Jersey, Princeton University Press, Princeton.

Gikandi, Simon, 1996, Maps of Englishness. Writing Identity in the Culture of Colonialism, Nueva York, Columbia University Press.

Grace, Sherril, 1982, "The Luminous Wheel” en Malcolm Lowry, Under the Volcano, Gordon Bowker (ed.), Houndmills y Londres, Macmillan, Casebook Series, pp. 152-171

Král, Françoise, 2009, Critical Identidies in Contemporary Anglophone Diasporic Literature, Houndsmill, Palgrave Macmillan. 
Miller, Andrew John, 2004, "Under the Nation-State: Modernist Deterritorialization in Malcolm Lowry's 'Under the Volcano"” Twentieth Century Literature, vol. 50, núm. 1 (Primavera, 2004) pp. 1-17, disponible en: http://www.jstor.org/stable/4149251 (consultado el 20/VII/2013)

Nicholls, Peter, 2009, Modernism. A Literary Guide, Houndmills, Palgrave Macmillan.

Lowry, Malcolm, 1947, Under the Volcano, Harmondsworth, Penguin / Jonathan Cape.

Era.

, 1964, Bajo el volcán, Raúl Ortiz y Ortiz (trad.), México, , 1967, The Selected Letters of Malcolm Lowry, Harvey Breit y Margerie Bonner Lowry (eds.), Harmondsworth, Penguin.

Said, Edward, 1993, Culture and Imperialism, Nueva York, Alfred A. Knopf.

Spivak, Gayatri C., "Reading the Satanic Verses" en Outside in the Teaching Machine, Nueva York y Londres, Routledge, pp. 217-242.

Veitch, Douglas W., 1978, Lawrence, Green and Lowry: The Fictional Landscape of Mexico, George Woodcock (prefacio), Ontario, Wilfrid Laurier University Press.

Walker, Ronald G., 1978, Infernal Paradise. Mexico and the Modern English Novel, Berkeley, University of California Press.

Wood, Barry, 1980, “The Strands of Novel, Confession, Anatomy and Romance" en Malcolm Lowry, Under the Volcano, Gordon Bowker (ed.), Houndmills y Londres, Macmillan, Casebook Series, pp. 142-151.

(Artículo recibido el 19 de junio de 2013; aceptado el 23 de septiembre de 2013). 
